Running head: DURATION OF JOB INSECURITY

\begin{tabular}{|c|}
\hline Currently in press at \\
Career Development International
\end{tabular}

Job Insecurity and Performance over Time: The Critical Role of Job Insecurity Duration

Maike E. Debus

University of Zurich

\author{
Dana Unger \\ University of East Anglia
}

Cornelius J. König

Saarland University

Author note:

Correspondence concerning this article should be addressed to Maike E. Debus, Universität Zürich, Arbeits- \& Organisationspsychologie, Binzmühlestrasse 14/12, 8050 Zürich, Switzerland. E-mail: m.debus@psychologie.uzh.ch

This article may not exactly replicate the final version published in Career Development International. It is not the copy of record. 


\begin{abstract}
Purpose. Research on the relationship between job insecurity and job performance has thus far yielded inconclusive results. The purpose of this conceptual paper is to offer a more dynamic perspective on the effects of job insecurity on job performance.

Approach. Drawing from cognitive appraisal theory, research on critical life events and stress reactions as well as more general theorizing around the role of time, this paper proposes that individuals' job performance reactions to job insecurity will be dynamic over time.
\end{abstract}

Findings. Adopting a person-centered perspective, this paper suggests that there are seven subpopulations that differ in their intra-individual job performance change patterns over time.

Research implications. This paper presents potential predictors of subpopulation membership and presents an agenda for future research.

Originality/value. This conceptual paper contributes to the literature by introducing a dynamic perspective to the study of job performance in the context of job insecurity. Delineating a set of open questions that follow from the presented theoretical arguments, the authors also hope to stimulate future research in the context of job insecurity and job performance.

Keywords: Job insecurity, job performance, duration, longitudinal 
Job Insecurity Duration and Job Performance

Commercial rivalries around the globe, government deregulation, and rapid technological developments have put re-organizations, mergers, acquisitions, and downsizing on the agenda of companies worldwide (e.g., Lee et al., 2018). As a result, many individuals experience a situation of job insecurity in which they are concerned about their future job permanence (e.g., Van Vuuren and Klandermans, 1990). Studies have demonstrated that perceived job insecurity relates to negative outcomes, such as reduced job satisfaction, commitment, and well-being, as well as higher turnover intentions (e.g., Cheng and Chan, 2008).

Yet, findings on the relationship between job insecurity and job performance can be described as 'mixed'- with studies either finding no (e.g., Sverke et al., 2002) or a slightly negative relationship (e.g., Cheng and Chan, 2008). To explain these findings, researchers have argued that the job insecurity-job performance relationship might be more complex than a simple linear relationship (e.g., Selenko et al., 2013; Staufenbiel and König, 2010), thereby also recommending the use of longitudinal research designs (see also Huang et al., 2013; Lam et al., 2015). In the present conceptual paper, we further this proposition by arguing that the duration of job insecurity and the appraisal of job insecurity are crucial for gaining a more holistic understanding in terms of job insecurity's effects on job performance.

There are several reasons why researchers should consider the notion of time when studying job insecurity. First, researchers have repeatedly pointed to the notion that stressors like job insecurity may not exert gradual effects, but that outcomes might evolve discontinuously (e.g., Sonnentag et al., 2014). Put differently, performance reactions to job insecurity might not emerge as soon as individuals start to experience job insecurity, but could occur after a certain amount of time has passed. Relatedly, studies on the stress responses of animals (Van Erp et al., 1994) and conceptual papers on the dynamics inherent 
to psychological phenomena (Frese and Zapf, 1988; Roe, 2008) have highlighted that determining a stressor's onset and duration are important for understanding the dynamic trajectory (i.e., the development over time) of its outcomes. For example, job performance might deteriorate first and improve again. Second, job insecurity may be viewed from a critical life event perspective. Research has shown that individuals who experience an initial shock moment after a critical event may also adapt to the event over time (Frederick and Loewenstein, 1999; Lucas, 2007). Thus, taking a longitudinal, within-person perspective appears necessary to uncover such patterns. Finally, Sverke et al. (2002) explicitly called for the study of job insecurity duration and its related processes over time, noting that "research dealing with such processes would make important contributions to the existing literature" (p. 259). Urging researchers to investigate this topic, Roe (2008) also highlighted that the literature tends to ignore the relevance of the duration of phenomena.

Here, we draw from theory on the general role of time in psychological phenomena (e.g., Roe, 2008), the literatures on critical life events (e.g., Lucas, 2007), and stress reactions (e.g., Frese and Zapf, 1988). We propose that for the duration of job insecurity, individuals' job insecurity appraisals may change - thus affecting their performance reactions. Notably, we argue that there may be differences in the way employees' job performance develops with prolonged experience of job insecurity. Thus, it is likely that there are different change patterns; that is, employees may comprise different subpopulations that differ in their intraindividual job performance trajectories over time. Building upon the idea that individuals develop in different systems of varying degrees of abstractness (Bronfenbrenner, 1977; 1994), we further delineate a set of variables that may predict to which subpopulation an individual belongs and present an agenda for future research.

To describe our arguments in a clear and easy-to-follow manner, we use two simplifications. First, we assume that as soon as employees start experiencing job insecurity, 
the perceived likelihood of losing their job remains constant, but - as noted above - that their cognitive appraisal of job insecurity can change over time. Second, we focus on job performance as a general concept without differentiating between sub-facets. We refer back to these simplifications in the discussion section of the paper.

\section{Theoretical Foundations}

In his call for a more temporal research strategy, Roe (2008) suggested three features of temporal phenomena: onset, duration, and dynamics. First, onset refers to when a phenomenon (in the present case, job insecurity) starts to appear "relative to some external time scale" (p. 43). Second, duration refers to the lifetime of a phenomenon; that is, whether a phenomenon "may be short-lived, long-lasting, or have some intermediate lifetime" (p. 43). Finally, dynamics refers to the variety of patterns that a phenomenon can display: These patterns can be described as growth, decline, or stability (Roe, 2008). Furthermore, Roe (2008) posits that different phenomena's features of onset, duration, and dynamics may be interrelated (see Table 3 of Roe, 2008). In the following, we focus on the dynamics of job performance for the duration of job insecurity as well as the relevance of appraisal processes in this context.

We apply Roe's (2008) conceptualizations and theoretically derive seven dynamic job performance change patterns (i.e., subpopulations) to which employees may belong during the time they are exposed to job insecurity. In line with this, Frese and Zapf (1988; see also Garst et al., 2000) argued that the relationships between stressors and reactions to stressors might not be uniform over time. Furthermore, Roe (2008) states that there can be different subpopulations with respect to the dynamics of a phenomenon. That is, the dynamic development of different phenomena does not necessarily have to be the same for all individuals. Transferred to our context, this reasoning implies that for one subpopulation the trajectory of job performance might be characterized by decline over time, whereas for 
another subpopulation the trajectory might be characterized by growth over time. Combining these two approaches, we predict that employees will show different trajectories of job performance for the duration of job insecurity.

The transactional theory of stress (Lazarus \& Folkman, 1984) states that after an event has occurred, individuals appraise its relevance as benign, irrelevant, a challenge, or a threat to their wellbeing. Parallels to the differentiation between challenge and threat can already be found in the concepts of eustress vs. distress (Selye, 1974) and are prominently featured in the challenge-hindrance framework developed by Cavanaugh et al. (2000; see also LePine et $a l ., 2005)$. According to this framework, stressors can threaten one's goal pursuit; in this case, these hindrance stressors can cause negative emotions. Yet, stressors can also be motivating (i.e., challenging); in this case, they have the potential to lead to positive emotions. Furthermore, Staufenbiel and König (2010) argued that a stressor can simultaneously be both a hindrance and a challenge (i.e., it can be ambivalent) and they found supporting evidence for the stressor job insecurity.

More specifically, job insecurity can be appraised as a hindrance stressor because it puts employees in a threatening situation where they fear losing something of value: their job. If an employee's job is insecure, this means that their situation is characterized by unpredictability (“Will I lose my job? And if so, when?") and uncontrollability, which puts a burden on the employee. Job insecurity likely hinders their ability to focus on the work that needs to be done and, thus, interferes with goal attainment. Furthermore, job insecure employees likely fear that losing their job threatens the monetary and non-monetary benefits that people acquire through working (Jahoda, 1982), and they do not want to belong to the marginalized group of the unemployed (Selenko et al., 2017).

At the same time, job insecurity can also be appraised as a challenge stressor because employees might hope that they can decrease the likelihood of losing their jobs by 
performing better (Staufenbiel and König, 2010). Shoss (2017, p. 1927) termed this aspect of job insecurity the "job preservation motivation." If supervisors notice how hard employees work, employees can demonstrate their high value to the organization, thus possibly safeguarding themselves from job loss. In addition, if staff collectively improve their work performance it could reduce the overall likelihood of layoffs (see Gilboa et al., 2008). Importantly, Staufenbiel and König (2010) do not assume employees who appraise job insecurity as a challenge stressor experience positive emotions. Positive emotions are only likely when an employee's efforts result in job security again, which likely leads to a feeling of relief and even pride.

\section{Delineating Job Performance Change Patterns}

Our model rests on the idea that job insecurity can be predominantly appraised as a hindrance or a challenge (or as irrelevant). Furthermore, it is possible that hindrance and challenge appraisal exist simultaneously and that their effects on job performance can cancel themselves out. We also posit that reappraisals have an impact on the job performance change patterns such that job performance can also fluctuate over time because the appraisals are not constant. For those employees who appraise job insecurity predominantly as a threat and, thus, as a hindrance stressor, the following three unstable patterns of job performance are possible: 1) continuous impact pattern, 2) sleeper effect pattern, and 3) initial impact pattern (see Frese and Zapf, 1988). If job insecurity is predominantly appraised as a challenge, the following three unstable patterns are possible: 4) initial motivation pattern, 5) delayed motivation pattern, and 6) continuous motivation pattern. Finally, if job insecurity is appraised as irrelevant or if it is appraised as both a hindrance and a challenge, the 7) stable pattern is conceivable. Figure 1 depicts the trajectories of these seven hypothesized subpopulations. We describe them in more detail below. 
1) For the continuous impact pattern, the longer employees experience job insecurity, the more their job performance will deteriorate. Employees in this pattern would perceive job insecurity predominantly and continuously as a threat without a reappraisal (see Lazarus and Folkman, 1984) and they would increasingly reduce their work efforts so that their job performance decreases. Instead of focusing on their work, these employees might redirect their personal resources such as energy and time (ten Brummelhuis and Bakker, 2012) to find a new job. For this pattern, the decline of job performance would stop at a certain asymptotical level because of a floor effect. That is, job performance cannot get poorer than "very poor". Alternatively, an employee whose job performance is worse than a certain threshold could be made redundant.

2) For the sleeper effect pattern, job performance remains stable after employees start perceiving job insecurity, but as the duration of job insecurity gets longer, detriments in employees' job performance will become detectable. In the beginning, employees would appraise job insecurity as irrelevant. Another possibility is that the challenge appraisal and the threat appraisal would be equally strong (Lazarus and Folkman, 1984). Yet, after a certain amount of time has passed, employees would start to reappraise job insecurity (primarily) as a threat, and, thus, as a hindrance stressor so that their job performance declines. For instance, witnessing how former colleagues are made redundant, surviving employees might change their mind about the relevance of job insecurity and re-appraise job insecurity as a threat to their jobs with their job performance suffering.

3) For the initial impact pattern, the level of job performance will first deteriorate after job insecurity sets in and then improve again, even though job insecurity would be still present. Consequently, the trajectory has a U-shape. A reason why job performance might increase again even though there is exposure to job insecurity is adaptation (Frederick and Loewenstein, 1999), in which the strength of the threat appraisal declines, thus resulting in a 
gradual improvement in job performance. Moreover, after a while, employees might feel that the job insecure situation is the new status quo without any imminent consequences for them. Thus, they would stop seeing job insecurity as a hindrance stressor and reappraise it as irrelevant (Lazarus and Folkman, 1984), which brings them back to their normal levels of job performance.

4) The initial motivation pattern refers to a curvilinear (inverted U) association between job insecurity duration and job performance. Appraising job insecurity as a challenge stressor, employees might be motivated at first to preserve their job and, thus, they would demonstrate improvements in their job performance (Shoss, 2017). Employees in a job insecure situation might be aware that their performance is being scrutinized and that they need to perform well (see Sackett et al., 1988). Consequently, they will show their peak or maximal job performance at one point after the onset of job insecurity. As time passes, however, employees would return to their typical level of job performance because they cannot sustain their maximal job performance for a prolonged period of time.

5) The delayed motivation pattern is characterized by a stable trajectory of job performance after employees start to experience job insecurity. However, as time passes, job performance improves. It is conceivable that in this pattern employees would appraise job insecurity first as irrelevant or as both a threat and a challenge, with no effects on their job performance. After a reappraisal takes place (Lazarus and Folkman, 1984), job insecurity would be predominantly perceived as a challenge stressor with positive effects on job performance. This reappraisal might be more likely for those employees who do not witness the lay-off of other (high-performing) colleagues (Sadri, 1996). It could also be due to a change in the intra-organizational communication underlining the relevance of high work performance for safeguarding one's job (Schweiger and Denisi, 1991). 
6) The continuous motivation pattern assumes that with prolonged duration of job insecurity, job performance improves continuously because job insecurity would be constantly appraised as a challenge (see Lazarus and Folkman, 1984). In this pattern, employees should be motivated to preserve their jobs. In contrast to the initial motivation and the delayed motivation patterns, no reappraisal of the job insecurity takes place for those in the continuous motivation pattern. Particularly those employees who are continuously reminded that job preservation is contingent on good performance (Shoss, 2017) should belong to this pattern. Due to a ceiling effect, job performance would reach a certain asymptotical level; that is, job performance cannot get better than "very good".

7) The stable pattern is characterized by job performance showing neither decline nor growth in times of job insecurity. If employees appraise job insecurity as irrelevant (Lazarus and Folkman, 1984), it is conceivable that there is a stable pattern of job performance. For instance, employees who are eligible to retire might find job insecurity neither threatening nor challenging (see Super, 1980). Furthermore, it is possible that employees are ambivalent about the situation of job insecurity; that is, they might appraise job insecurity as a threat and as a challenge to the same degree. These employees are torn between the fear of losing their job and their ambitions to fight for it. Due to the simultaneity of both appraisals (see Staufenbiel and König, 2010), it is likely that a stable performance trajectory emerges.

\section{Predictors of Pattern Membership}

In the following, we present conceivable predictor variables of individuals' pattern membership by drawing from Bronfenbrenner's $(1977 ; 1994)$ ecological model of human development. This model views the individual as developing in five higher-level environments and considers the role of individuals' chronological age and historical time. We think it is crucial to consider these layers when deriving the most pertinent predictors of the proposed job performance change patterns. First, the individual is located at the 'center' of 
Bronfenbrenner's model, which comprises individual genetically inherited and socially acquired traits. Second, the microsystem refers to all "relations between the developing person and environment in an immediate setting" (Bronfenbrenner, 1977, p. 514). Third, the mesosystem comprises the interactions between two or more microsystems, for instance the interaction of one's nuclear family with one's work (Bronfenbrenner, 1994). Fourth, the exosystem entails major societal structures such as neighborhoods, agencies, or communication and transportation facilities (Bronfenbrenner, 1977). Fifth, the macrosystem pertains "to the belief systems, bodies of knowledge, material resources, customs, life styles, opportunity structures, hazards, and life course options" (Bronfenbrenner, 1994, p. 40). Finally, the chronosystem encompasses the historical time and the personal development (Bronfenbrenner, 1994). Although several factors may predict a person's pattern membership, the ones that we delineate in the following constitute those factors that appear most relevant from a theoretical perspective.

In terms of the individual characteristics, we posit that core-self evaluations (CSE) and, in particular, internal locus of control, might be relevant here. CSE refer to fundamental evaluations about oneself (Judge et al., 1997), one's abilities, and control; internal locus of control describes a person's expectancy “that rewards, reinforcements or outcomes in life are controlled either by one's own actions" vs. "by other factors" (Spector, 1988, p. 335).

Because individuals high on CSE and internal locus of control tend to view the world in more positive and controllable terms (Debus et al., 2014; Kammeyer-Mueller et al., 2009; Rotter, 1966), job insecurity might be more readily appraised as a challenge to be mastered. Thus, individuals high on CSE and internal locus of control might believe that improving job performance helps to safeguard their employment in times of job insecurity. Accordingly, we suggest that individuals with high CSE and an internal locus of control are more likely to be members of a pattern where job performance improves during the exposure to job insecurity 
(i.e., the initial impact pattern, the initial motivation pattern, the delayed motivation pattern, the continuous motivation pattern).

In terms of the microsystem, employees' relations with their employers might be relevant. The psychological contract (the unwritten set of expectations between employees and their employers; Rousseau, 1989) captures this employment relation. If job security is not an essential element of the deal - such as in the case of temporary contract workers employees might appraise job insecurity as irrelevant. Thus, the stable pattern would be more pertinent. However, employees whose psychological contract includes job security might react differently. Based on social-exchange theory (e.g., Thibaut and Kelley, 1959), these employees might experience a contract breach when perceiving job insecurity; thus, they might be more likely to retaliate continuously with poorer job performance (i.e., show the continuous impact pattern).

In terms of the mesosystem, the interrelations between the workplace and one's romantic partner appear particularly relevant. For work-linked couples, these interrelations are very strong because both partners in the relationship share the same occupation, the same workplace, or both (Halbesleben et al., 2010). Recent studies (e.g., Fritz et al., 2018; Park and Haun, 2017) estimate that the percentage of work-linked couples is at least 13\%. Further pointing to the relevance of this status, Halbesleben et al. (2010), for example, demonstrated that being work-linked acts as a moderator of relationships between the partner's social support and one's own emotional exhaustion. Similarly, the negative effects of both partners' job insecurity might be amplified within these work-linked couples (see Debus and Unger, 2017) making it more likely that employees appraise job insecurity as a threat. Accordingly, the pertinent patterns among work-linked couples might include a decline in job performance (e.g., continuous impact pattern, sleeper effect pattern, and initial impact pattern). 
In terms of the exosystem, the socio-economic status (SES) of a neighborhood might be crucial for at least two reasons. First, low-SES neighborhoods (as compared to high-SES areas) are characterized by lower-quality physical and social conditions such as noise, crime, and low-quality homes (Evans, 2004). Due to these living conditions, employees in low-SES neighborhoods might not be able to adapt to yet another stressor such as job insecurity (see van Woerkom et al., 2016). Second, employees in low-SES neighborhoods interact more often with unemployed individuals, who presumably were not able to safeguard their jobs. Being surrounded by negative role models (Bandura, 1986), employees from these neighborhoods would be less likely to appraise job insecurity as a challenge that can be mastered. Hence, these individuals might be less likely to belong to any of the patterns that would entail an improvement in job performance with prolonged job insecurity (i.e., the initial impact pattern, the initial motivation pattern, the delayed motivation pattern, or the continuous motivation pattern).

In terms of the macrosystem, the country-level socio-economic development might play a role - with the social safety net being an indicator of this development. The social safety net refers to governmental regulation of the labor market and social protection programs that protect workers from job loss and significant income declines (e.g., Blank, 1994). Within the safety net, unemployment benefits are a major instrument that may protect the unemployed against slipping into poverty. Previous research has already demonstrated that employees from countries with a weak (vs. strong) safety net react particularly negatively to job insecurity (Debus et al., 2012). Accordingly, we assume that employees from countries with a weak safety net are more likely to appraise job insecurity as a threat and are, thus, more likely to belong to a job performance change pattern that includes decline (e.g., the continuous impact pattern, the sleeper effect pattern, the initial impact pattern). 
Finally, in terms of the chronosystem, we suggest that recurrent job insecurity and unemployment experiences (see Roe, 2008) might play an important role. Research on repeated experiences of unemployment has demonstrated that individuals' reactions appear to worsen with each spell of unemployment (Luhmann and Eid, 2009). When employees with a history of unemployment or job insecurity experience yet another phase of job insecurity, they might appraise job insecurity as a threat that must not be underestimated (as opposed to those who have not had these experiences). Thus, individuals with a prior unemployment or job insecurity history might be more likely to show one of the pertinent decline patterns (e.g., the continuous impact pattern, the sleeper effect pattern, or the initial impact pattern).

\section{Discussion}

We have argued that to better understand how job insecure individuals' job performance changes over time, it is important to consider the changes in individuals' job insecurity appraisals for the duration of job insecurity. Drawing from cognitive appraisal theory, research on critical life events and stress reactions, as well as more general theorizing around the role of time in psychological phenomena, we proposed the existence of seven longitudinal job performance change patterns, along with potential predictors.

Taking into account job insecurity duration can enrich the current literature in several ways. First, we adopted a person-centered perspective (e.g., Wang et al., 2013) by proposing the existence of different job performance change patterns that might evolve with prolonged duration of job insecurity. Classical longitudinal within-person research focuses on intraindividual changes of variables or their relationships over time, thereby assuming that trajectories or relationships will be uniform across individuals. It, thus, constitutes a variablecentered approach. In contrast, by taking a person-centered perspective, we assumed that employees may belong to different subpopulations rather than forming a homogeneous mass - an aspect that has been largely ignored in prior theorizing and research on job insecurity. 
Such a perspective can allow for a more precise and more valid description of job insecurity's effects on performance while also providing a further explanation for the rather inconclusive findings in the literature (Cheng and Chan, 2008; Lee et al., 2018). Second, we account for the notion of 'time' - specifically duration - as a crucial aspect when addressing performance outcomes of job insecurity. In doing so, we are able to explicitly address potential dynamics of job performance.

\section{An Agenda for Future Research and Potential Challenges}

Our arguments suggest several open research questions. First, future studies may want to examine which of the proposed patterns exist and how common they are relative to each other. Although we provided theoretically derived reasons for each of the suggested seven change patterns, empirical research is warranted. Future research is also needed to test the factors that may predict a person's membership of a specific job performance change pattern. Second, it remains to be determined which specific time period underlies the proposed job performance change patterns. On the one hand, stressor appraisal is considered a process that happens on a short-term basis (Lazarus, 2001), thus suggesting that performance reactions might occur relatively fast (e.g., a weekly basis). On the other hand, resource-oriented approaches (such as Hobfoll's conservation of resources theory, Hobfoll et al., 2018) would suggest that reactions to job insecurity happen on a rather long-term basis (e.g., a monthly basis) (for a similar argument see De Witte et al., 2016). Third, we would further recommend explicitly examining whether the primary appraisal of job insecurity as threatening, challenging, or irrelevant explains the link between the duration of job insecurity and the dynamics of job performance. On a related note, it might be worthwhile to investigate the secondary appraisal of coping resources such as energy, social support, and training in the present context (see Lazarus \& Folkman, 1984). Finally, future research may shed light on how employees make sense of their experienced job insecurity. ${ }^{1}$ Sensemaking is the "process 
through which people work to understand issues or events [that...] violate expectations" (Maitlis and Christianson, 2014, p. 57). Weick (1995) posits that sensemaking is triggered in situations that are ambiguous or uncertain — two features that characterize job insecurity. Greenhalgh and Jick (1989) have already provided a quantitative account of how survivors in a merged company make sense of their situation. We particularly advocate researching what the dynamic process entails in which employees make sense of their job insecurity experience (e.g., researching which cues employees attend to during the sensemaking process).

Clearly, the proposed model is associated with some challenges. First, we argued that employees' level of perceived job insecurity will remain constant after its onset. We did so to describe our assumptions in an easy-to-follow manner. Yet, this reasoning is likely an oversimplification because scholars have demonstrated that job insecurity perceptions can fluctuate over time (e.g., Schreurs et al., 2012). Integrating this dynamic aspect into our theoretical arguments implies a "growth on growth" model (see Singer and Willett, 2003, pp. 295), meaning that changes in perceived job insecurity would likewise affect changes in job performance. Second, we only focused on job performance as a general concept. Nevertheless, job performance can also be broken down into in-role behavior (i.e., performance that is formally required), organizational citizenship behavior (OCB; i.e., positive behavior that goes beyond in-role behavior), and counterproductive work behavior (CWB; i.e., behavior that harms the well-being of organizations and their members) (see, e.g., Rotundo and Sackett, 2002). Whereas in-role behavior and OCB are highly correlated (Hoffman et al., 2007), meta-analyses have reported much smaller correlations between CWB and OCB (Dalal, 2005) and between CWB and in-role behavior (Carpenter and Berry, 2017). Thus, it seems particularly worthwhile to explore how CWB develops for the duration of job insecurity. Third, our model focuses on the shift from job security to job insecurity, although it is also possible that employees experience a shift from job insecurity to job 
security (e.g., because their employer has been bought by another company that is wellknown for not firing people). Thus, there might be likewise different subpopulations that differ in their job performance change patterns over time.

Finally, if perceived job insecurity induces a job preservation motivation (Shoss, 2017), this could mean that employees work harder, but it could also mean that they may pretend to work harder. Thus, they might engage in impression management (see Huang et al., 2013). Given that this kind of impression management is likely geared towards their managers (because it is their managers who decide who will be made redundant), future research on the relationship between job insecurity and performance should not only rely on supervisor performance ratings, but also include others' ratings as well. ${ }^{2}$

\section{Practical Implications}

Taking into account how job insecurity appraisals may change with the duration of job insecurity has several implications for practice. First, we would like to highlight that we agree with predominant thinking in the field that job insecurity is mainly a hindrance stressor (see also Staufenbiel and König, 2010) that should be avoided whenever possible (Shoss, 2017). Hence, although we pointed to potentially challenging and motivating aspects, organizations should by no means capitalize on these effects by deliberately creating job insecurity among their subordinates, especially given the vast amount of negative attitudinal and health-related outcomes. Organizations should do their best to avoid job insecurity among their employees by employing a trustful and open communication strategy (Keim et al., 2014).

Second, our aforementioned arguments imply that performance reactions to job insecurity may be dynamic over time and differ between individuals. Thus, if managers observe no change in job performance among their subordinates at a given moment in time, this may not imply that their job performance is or was unaffected by their job insecurity. 
Instead, it might be also the case that (a) employees have already adapted to this situation (as suggested by the initial impact pattern), (b) that they have, after an initial burst, returned to their previous level of performance (as suggested by the initial motivation pattern), or (c) that job insecurity still has an impact at a later point in time (as suggested by the sleeper effect pattern). Thus, we advise managers to pay attention to their employees on a continuous basis.

\section{Conclusion}

This paper develops a novel and dynamic theoretical conceptualization of job insecurity by building on the idea that employees' reactions to perceived job insecurity might change during the time they are exposed to this experience. Furthermore, our approach anticipates between-person differences of job performance change patterns for the duration of job insecurity. The attention devoted to duration and appraisal processes could help to explain the puzzlingly small relationship found between job insecurity and job performance. Moreover, this approach might be applied to other studies that also take into account the dynamic nature of reactions to stressors that entail processes that evolve over time, with increases and decreases, as well as (inverted) U-shapes. 


\section{References}

Bandura, A. (1986), Social foundations of thought and action: A social cognitive theory, Prentice-Hall, Englewood-Cliffs, NJ.

Blank, R.M. (1994), Social protection versus economic flexibility: Is there a trade-off?, University of Chicago Press, Chicago, IL.

Bronfenbrenner, U. (1977), "Toward an experimental ecology of human development", American Psychologist, Vol. 32 No. 7, pp. 513-531.

Bronfenbrenner, U. (1994), "Ecological models of human development", International encyclopedia of education, 2nd ed, Oxford, England, Elsevier, pp. 1643-1647.

Carpenter, N.C. and Berry, C.M. (2017), "Are counterproductive work behavior and withdrawal empirically distinct? A meta-analytic investigation", Journal of Management, Vol. 43 No. 3, pp. 834-863.

Cavanaugh, M.A., Boswell, W.R., Roehling, M.V. and Boudreau, J.W. (2000), "An empirical examination of self-reported work stress among U.S. managers", Journal of Applied Psychology, Vol. 85 No. 1, pp. 65-74.

Cheng, G.H.-L. and Chan, D.K.-S. (2008), "Who suffers more from job insecurity? A metaanalytic review", Applied Psychology: An International Review, Vol. 57 No. 2, pp. 272-303.

Dalal, R.S. (2005), "A meta-analysis of the relationship between organizational citizenship behavior and counterproductive work behavior", Journal of Applied Psychology, Vol. 90 No. 6, pp. 1241-1255.

De Witte, H., Pienaar, J. and De Cuyper, N. (2016), "Review of 30 years of longitudinal studies on the association between job insecurity and health and well-being: Is there causal evidence?", Australian Psychologist, Vol. 51 No. 1, pp. 18-31. 
Debus, M.E., König, C.J. and Kleinmann, M. (2014), "The building blocks of job insecurity: The impact of environmental and person-related variables on job insecurity perceptions", Journal of Occupational and Organizational Psychology, Vol. 87 No. 2, pp. $329-351$.

Debus, M.E., Probst, T.M., König, C.J. and Kleinmann, M. (2012), "Catch me if I fall! Enacted uncertainty avoidance and the social safety net as country-level moderators in the job insecurity-job attitudes link", Journal of Applied Psychology, Vol. 97 No. 3, pp. 690-698.

Debus, M.E. and Unger, D. (2017), "The interactive effects of dual-earner couples' job insecurity: Linking conservation of resources theory with crossover research", Journal of Occupational and Organizational Psychology, Vol. 90 No. 2, pp. 225-247.

Evans, G.W. (2004), "The environment of childhood poverty", American Psychologist, Vol. 59 No. 2, pp. 77-92.

Frederick, S. and Loewenstein, G. (1999), "Hedonic adaptation", in Kahneman, D., Diener, D. and Schwarz, N. (Eds.), Well-being: The foundations of hedonic psychology, Russell Sage Foundation, New York, pp. 302-329.

Frese, M. and Zapf, D. (1988), "Methodological issues in the study of work stress: Objective vs. subjective measurement of work stress and the question of longitudinal studies", in Cooper, C.L. and Payne, R. (Eds.), Causes, coping and consequences of stress at work, Wiley, Chichester, UK, pp. 375-411.

Fritz, C., Park, Y. and Shepherd, B.R. (2018), "Workplace incivility ruins my sleep and yours: The costs of being in a work-linked relationship", Occupational Health Science. Advance online publication. 
Garst, H., Frese, M. and Molenaar, P.C.M. (2000), "The temporal factor of change in stressor-strain relationships: A growth curve model on a longitudinal study in East Germany", Journal of Applied Psychology, Vol. 85 No. 3, pp. 417-438.

Gilboa, S., Shirom, A., Fried, Y. and Cooper, C. (2008), "A meta-analysis of work demand stressors and job performance: Examining main and moderating effects", Personnel Psychology, Vol. 61 No. 2, pp. 227-271.

Greenhalgh, L. and Jick, T.D. (1989), "Survivor sense making and reactions to organizational decline: Effects of individual differences", Management Communication Quarterly, Vol. 2 No. 3, pp. 305-327.

Halbesleben, J.R.B., Zellars, K.L., Carlson, D.S., Perrewe, P.L. and Rotondo, D. (2010), "The moderating effect of work-linked couple relationships and work-family integration on the spouse instrumental support-emotional exhaustion relationship", Journal of Occupational Health Psychology, Vol. 15 No. 4, pp. 371-387.

Hobfoll, S.E., Halbesleben, J., Neveu, J.P. and Westman, M. (2018), "Conservation of resources in the organizational context: The reality of resources and their consequences", Annual Review of Organizational Psychology and Organizational Behavior, Vol. 5, pp. 103-128.

Hoffman, B.J., Blair, C.A., Meriac, J.P. and Woehr, D.J. (2007), "Expanding the criterion domain? A quantitative review of the OCB literature", Journal of Applied Psychology, Vol. 92 No. 2, pp. 555-566.

Huang, G.H., Zhao, H.H., Niu, X.Y., Ashford, S.J. and Lee, C. (2013), "Reducing job insecurity and increasing performance ratings: Does impression management matter?", Journal of Applied Psychology, Vol. 98 No. 1, pp. 852-862.

Jahoda, M. (1982), Employment and unemployment: A social-psychological analysis, Cambridge University Press, Cambridge, MA. 
Judge, T.A., Locke, E.A. and Durham, C.C. (1997), "The dispositional causes of job satisfaction: A core evaluations approach", Research in Organizational Behavior, Vol. 19, pp. 151-188.

Kammeyer-Mueller, J.D., Judge, T.A. and Scott, B.A. (2009), "The role of core selfevaluations in the coping process", Journal of Applied Psychology, Vol. 94 No. 1, pp. 177-195.

Keim, A.C., Landis, R.S., Pierce, C.A. and Earnest, D.R. (2014), "Why do employees worry about their jobs? A meta-analytic review of predictors of job insecurity", Journal of Occupational Health Psychology, Vol. 19 No. 3, pp. 269-290.

Lam, C.F., Liang, J., Ashford, S.J. and Lee, C. (2015), "Job insecurity and organizational citizenship behavior: Exploring curvilinear and moderated relationships", Journal of Applied Psychology, Vol. 100 No. 2, pp. 499-510.

Lazarus, R.S. (2001), Emotion and adaptation, Springer, New York, NY.

Lazarus, R.S. and Folkman, S. (1984), Stress, appraisal, and coping, Springer, New York, NY.

Lee, C., Huang, G.-H. and Ashford, S.J. (2018), "Job insecurity and the changing workplace: Recent developments and the future trends in job insecurity research", Annual Review of Organizational Psychology and Organizational Behavior, Vol. 55, pp. 335-359.

LePine, J.A., Podsakoff, N.P. and LePine, M.A. (2005), "A meta-analytic test of the challenge stressor-hindrance stressor framework: An explanation for inconsistent relationships among stressors and performance", Academy of Management Journal, Vol. 48 No. 5, pp. 764-775.

Lucas, R.E. (2007), "Adaptation and the set-point model of subjective well-being: Does happiness change after major life events?", Current Directions in Psychological Science, Vol. 16 No. 2, pp. 75-79. 
Luhmann, M. and Eid, M. (2009), "Does it really feel the same? Changes in life satisfaction following repeated life events", Journal of Personality and Social Psychology, Vol. 97 No. 2, pp. 363-381.

Maitlis, S. and Christianson, M.K. (2014), "Sensemaking in organizations: Taking stock and moving forward", Academy of Management Annals, Vol. 8 No. 1, pp. 57-125.

Park, Y. and Haun, V.C. (2017), "Dual-earner couples' weekend recovery support, state of recovery, and work engagement: Work-linked relationship as a moderator", Journal of Occupational Health Psychology, Vol. 22 No. 4, pp. 455-466.

Roe, R.A. (2008), "Time in applied psychology: The study of "What Happens" rather than "What Is"", European Psychologist, Vol. 13 No. 1, pp. 37-52.

Rotter, J.B. (1966), "Generalized expectancies for internal versus external control of reinforcement", Psychological Monographs: General and Applied, Vol. 80 No. 1, pp. $1-28$.

Rotundo, M. and Sackett, P.R. (2002), "The relative importance of task, citizenship, and counterproductive performance to global ratings of job performance: A policycapturing approach", Journal of Applied Psychology, Vol. 87 No. 1, pp. 66-80.

Rousseau, D.M. (1989), "Psychological and implied contracts in organizations", Employee Responsibilities and Rights Journal, Vol. 2 No. 2, pp. 121-139.

Sackett, P.R., Zedeck, S. and Fogli, L. (1988), "Relations between measures of typical and maximum job-performance", Journal of Applied Psychology, Vol. 73 No. 3, pp. 482486.

Sadri, G. (1996), "Reflections: The impact of downsizing on survivors - some findings and recommendations", Journal of Managerial Psychology, Vol. 11 No. 4, pp. 56-59.

Schreurs, B.H.J., Van Emmerik, I.J.H., Günter, H. and Germeys, F. (2012), "A weekly diary study on the buffering role of social support in the relationship between job insecurity 
and employee performance", Human Resource Management, Vol. 51 No. 2, pp. 259279.

Schweiger, D.M. and Denisi, A.S. (1991), "Communication with employees following a merger: A longitudinal field experiment", Academy of Management Journal, Vol. 34 No. 1, pp. 110-135.

Selenko, E., Mäkikangas, A., Mauno, S. and Kinnunen, U. (2013), "How does job insecurity relate to self-reported job performance? Analysing curvilinear associations in a longitudinal sample", Journal of Occupational and Organizational Psychology, Vol. 86 No. 4 , pp. $522-542$.

Selenko, E., Mäkikangas, A. and Stride, C.B. (2017), "Does job insecurity threaten who you are? Introducing a social identity perspective to explain well-being and performance consequences of job insecurity", Journal of Organizational Behavior, Vol. 38 No. 6, pp. 856-875.

Shoss, M.K. (2017), "Job insecurity: An integrative review and agenda for future research", Journal of Management, Vol. 43 No. 6, pp. 1911-1939.

Singer, J.D. and Willett, J.B. (2003), Applied longitudinal data analysis: Modeling change and event occurrence, Oxford University Press, New York, NY.

Sonnentag, S., Pundt, A. and Albrecht, A. (2014), "Temporal perpectives on job stress", in Shipp, A.J. and Fried, Y. (Eds.), Time and work: How time impacts individuals, Psychology Press, Hove, UK, pp. 111-140.

Spector, P.E. (1988), "Development of the Work Locus of Control Scale", Journal of Occupational Psychology, Vol. 61 No. 4, pp. 335-340.

Staufenbiel, T. and König, C.J. (2010), "A model for the effects of job insecurity on performance, turnover intention, and absenteeism.", Journal of Occupational and Organizational Psychology, Vol. 83 No. 1, pp. 101-117. 
Super, D.E. (1980), "A life-span, life-space approach to career-development", Journal of Vocational Behavior, Vol. 16 No. 3, pp. 282-298.

Sverke, M., Hellgren, J. and Näswall, K. (2002), "No security: A meta-analysis and review of job insecurity and its consequences", Journal of Occupational Health Psychology, Vol. 7 No. 3, pp. 242-264.

ten Brummelhuis, L.L. and Bakker, A.B. (2012), "A resource perspective on the work-home interface", American Psychologist, Vol. 67 No. 7, pp. 545-556.

Thibaut, N. and Kelley, H. (1959), The social psychology of groups, Wiley, New York, NY. Van Erp, A.M.M., Kruk, M.R., Meelis, W. and Willekens-Bramer, D.C. (1994), "Effect of environmental stressors on time-course, variability and form of self-grooming in the rat: Handling, social contact, defeat, novelty, restraint and fur moistening", Behavioural Brain Research, Vol. 65 No. 1, pp. 47-55.

Van Vuuren, T. and Klandermans, P.G. (1990), "Individual reactions to job insecurity: An integrated model", in Drenth, P.J.D., Sergeant, J.A. and Takens, R.J. (Eds.), European perspectives in psychology, Wiley, Chichester, England, pp. 133-146.

van Woerkom, M., Bakker, A.B. and Nishii, L.H. (2016), "Accumulative job demands and support for strength use: Fine-tuning the job demands-resources model using conservation of resources theory", Journal of Applied Psychology, Vol. 101 No. 1, pp. $141-150$.

Wang, M., Sinclair, R.R., Zhou, L. and Sears, L.E. (2013), "Person-centered analysis: Methods, applications, and implications for occupational health psychology", in Sinclair, R.R., Wang, M. and Tetrick, L.E. (Eds.), Research methods in occupational health psychology: Measurement, design, and data analysis, Routledge/Taylor \& Francis Group, New York, NY, pp. 349-373.

Weick, K.E. (1995), Sensemaking in organizations, Sage, Thousand Oaks, CA. 


\section{Footnotes}

[1] We would like to thank the Anonymous Reviewer 1 for contributing this idea.

[2] We would like to thank the Anonymous Reviewer 1 for contributing this idea. 


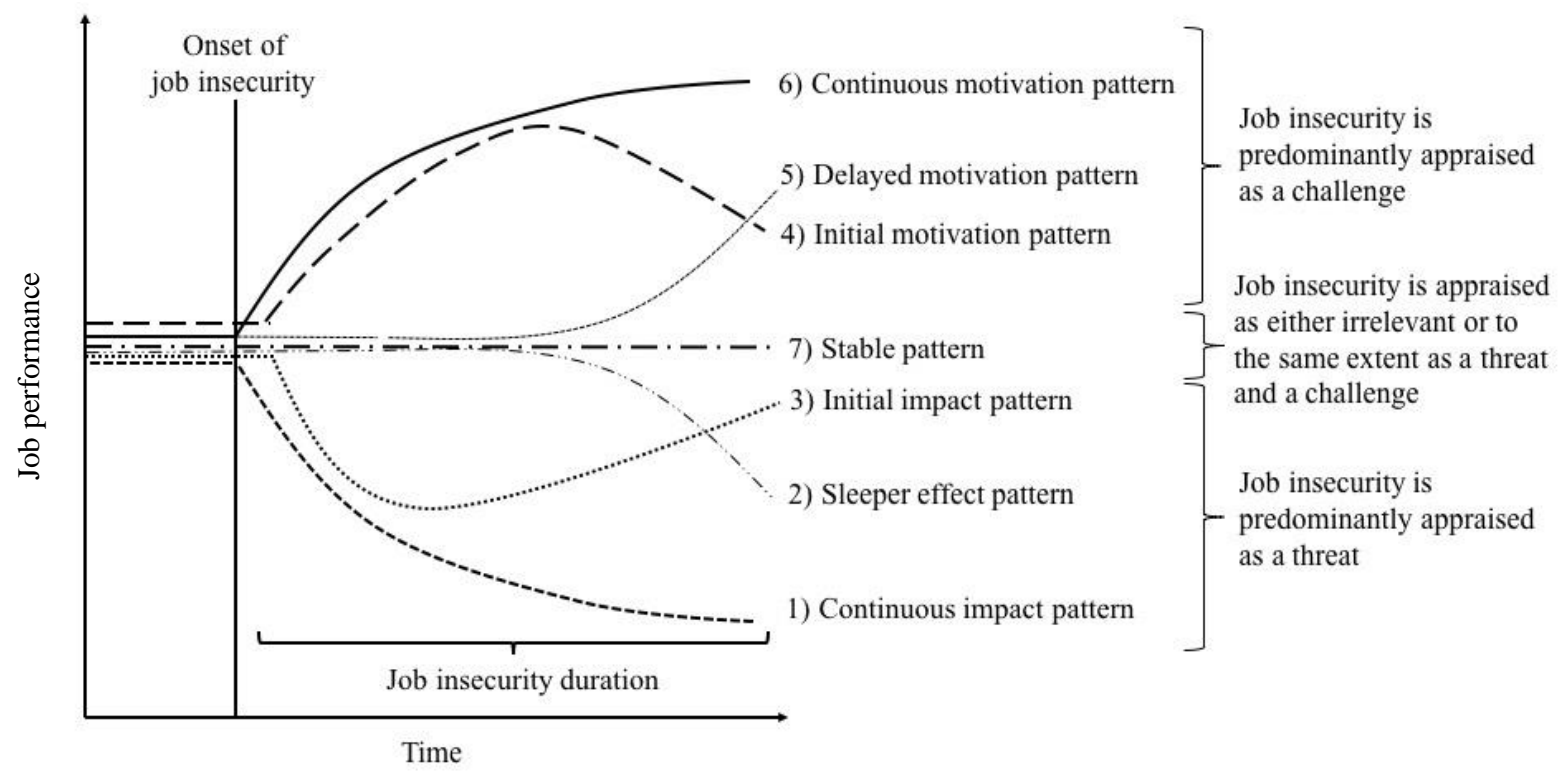

Figure 1. Proposed patterns of job performance trajectories for the duration of job insecurity 